\title{
Analisis Perbandingan Algoritma Decision Tree (C4.5) Dan K-Naive Bayes Untuk Mengklasifikasi Penerimaan Mahasiswa Baru Tingkat Universitas
}

\author{
Suyadi \\ Magister Teknik Informatika \\ Universitas Amikom Yogyakarta \\ E-mail: suyadia00@gmail.com \\ Arief Setyanto dan Hanif Al Fattah \\ Magister Teknik Informatika \\ Universitas Amikom Yogyakarta \\ E-mail : arief_s@amikom.ac.id, hanif.a@amikom.ac.id
}

\begin{abstract}
ABSTRAK
Profil PMB (Penerimaan Mahasiswa Baru) mahasiswa dari beberapa periode mempunyai data yang melimpah sehingga bisa digunakan untuk penelitian. Data tersebut berupa keterangan mahasiswa dari jurusan asal, NEM dan jurusan sekarang. Mengklasifikasi data profil PMB mahasiswa di tingkat Universitas di Yogyakarta dapat mengetahui mayoritas peserta didik. Membandingkan beberapa algoritma sangat dibutuhkan untuk mengetahui algoritma terbaik. Klasifikasi merupakan algoritma pengelompokan yang mempunyai beberapa algoritma diantaranya adalah Decision Tree (C4.5) dan K-Naive Bayes. Decision Tree (C4.5) merupakan algoritma dengan pohon keputusan, sedangkan K-Naive Bayes merupakan algoritma kemungkinan yang akan terjadi. Analisa ini menggunakan Rapidminer yang merupakan software analisa data dngan fitur beberapa algoritma yang mudah untuk dioperasikan. Kedua algoritma mempunyai hasil dengan data yang besar yaitu 1504 mahasiswa, Decision tree (C4.5) mempunyai akurasi $81,84 \%$ dan akurasi error $18,16 \%$, sedangkan K-Naive Bayes $85,12 \%$ dan akurasi error 14,88\%. Sedangkan dengan data yang lebih kecil Decision tree (C4.5) mempunyai akurasi $100 \%$ sedangkan kan K-Naive Bayes mempunyai akurasi yang sama dengan Decision Tree (C4.5) yaitu 100\%.
\end{abstract}

Kata Kunci: Data mining, Klasifikasi, Komparasi, Decision Tree (C4.5), K-Naive Bayes.

\section{ABSTRACT}

Profile of PMB (New Student Admissions) students from several periods have abundant data that can be used for research. The data is in the form of student information from the majors of origin, NEM and majors now. Classifying the PMB profile data of students at the University level in Yogyakarta can know the majority of learners. Comparing some algorithms is needed to find out the best algorithm. Classification is a grouping algorithm that has several algorithms such as Decision Tree (C4.5) and K-Naive Bayes. Decision Tree (C4.5) is an algorithm with decision tree, while K-Naive Bayes is the likely algorithm that will occur. This analysis uses Rapidminer which is a data analysis software with features of several algorithms that are easy to operate. Both algorithms have results with large data of 1504 students, Decision tree (C4.5) has an accuracy of $81.84 \%$ and an error accuracy of $18.16 \%$, while K-Naive Bayes $85.12 \%$ and accuracy of error $14.88 \%$. Whereas with smaller data the Decision tree (C4.5) has 100\% accuracy whereas K-Naive Bayes has the same accuracy as Decision Tree (C4.5) that is $100 \%$.

Keywords: Data mining, Classification, Comparison, Decision Tree (C4.5), K-Naive Bayes 


\section{PENDAHULUAN}

Membandingkan antar algoritma Algoritma klasifikasi untuk menganalisa dan mengklasifikasikan data PMB historikal mahasiswa, contoh : Algoritma Decision Tree (C4.5) dan K-Naive Bayes paling banyak digunakan untuk mengklasifikasi dan memprediksi. Tujuan utama penelitian ini adalah mengetahui pentingnya data historikal sebagai pengaruh terhadap akurasi untuk mengklasifikasi penerimaan mahasiswa baru. Makalah ini juga bertujuan mengidentifikasi algoritma terbaik di antara dua pilihan algoritma klasifikasi Decision Tree (C4.5) dan K-Naive Bayes. Hasilnya akan menunjukkan keakurasian yang dicapai dengan Parameter Standart dalam mengklasifikasikan tingkat risiko secara akurat.

Dicesion tree merupakan suatu teknik menemukan kumpulan pola atau fungsi yang mendeskripsikan serta memisahkan kelas data yang satu dengan yang lainnya untuk menyatakan objek tersebut masuk pada kategori tertentu dengan melihat kelakuan dan atribut dari kelompok yang telah didefinisikan. Dicesion Tree (C4.5) merupakan algoritma untuk mengklasifikasikan apa yang akan terjadi di masa depan untuk memperoleh hasil yang maksimal. Decision Tree (C4.5) adalah algoritma pembelajaran yang mengimplementasikannya pencarian heuristik (penemuan) yang cukup sebdaning menggunakan pohon keputusan [1].

Algoritma K-Naive Bayes bahwa dalam kumpulan data dua atribute mungkin saling bergantung satu sama lain tapi ini ketergantungan dapat didistribusikan secara merata di setiap atribut. K-Naive Bayes merupakan algoritma data mining yang dapat digunakan untuk melakukan klasifikasi, dan merupakan algoritma yang akan memberikan hasil kemungkinan yang akan terjadi di masa akan datang dari hasil klasifikasi. K-Naive Bayes pernah diterapakan untuk mengklasifikasikan data berdimensi tinggi. Data berdimensi tinggi yang dimaksud adalah data yang memiliki proporsi atribut yang tidak relevan. Percobaan dilakukan dengan menggunakan bagian dokumen dan gen microarray data yang menunjukkan efisiensi yang sangat memuaskan dengan presentase sekitar $98 \%$ [2].

Dalam penelitian mereka [3], menyajikan add-on ke kerangka Rapidminer yang mendukung pengguna selama tahap pemodelan dengan merekomendasikan operasi tambahan untuk dimasukkan ke dalam mesin yang saat ini dikembangkan dengan alur kerja. Model $R$ [4] adalah software statistik yang bekerja dengan formulasi model matematis sementara Rapidminer dapat bekerja secara efisien dengan menggunakan operator yang disediakan dalam bentuk blok untuk membuat alur kerja analisis data yang spesifik atau karakteristik produk. Penelitian ini menggunakan Rapidminer karena data yang diteliti berupa profil PMB mahasiswa dan terdiri dari beberapa atribut yang berisi value yang isinya abjad. Sehingga dibutuhkan software data mining untuk pengolah data berupa abjad untuk memudahkan.

\section{METODOLOGI PENELITIAN}

\subsection{Data Mining}

Data Mining adalah Serangkaian proses untuk menggali nilai tambah berupa informasi yang selama ini tidak diketahui secara manual dari suatu basis data dengan melakukan penggalian pola-pola dari data dengan tujuan untuk memanipulasi data menjadi informasi yang lebih berharga yang diperoleh dengan cara mengekstraksi dan mengenali pola yang penting atau menarik dari data yang terdapat dalam basis data. Data cleaning (untuk menghilangkan noise data yang tidak konsisten). Data integration (di mana sumber data yang terpecah dapat disatukan). Data selection (di mana data yang relevan dengan tugas analisis dikembalikan ke dalam database). Data transformation (di mana data berubah atau bersatu menjadi bentuk yang tepat untuk menambang dengan ringkasan performa atau operasi agresi). Knowledge Discovery (proses esensial di mana metode yang intelejen digunakan untuk mengekstrak pola data). Pattern evolution (untuk mengidentifikasi pola yang benar-benar menarik yang mewakili pengetahuan berdasarkan atas beberapa tindakan yang menarik). Knowledge presentation (di mana gambaran teknik visualisasi 
dan pengetahuan digunakan untuk memberikan pengetahuan yang telah ditambang kepada user).

\subsection{Klasifikasi}

Klasifikasi ialah suatu kegiatan yang mengelompokkan benda yang memiliki beberapa ciri yang sama dan memisahkan benda yang tidak sama. Dalam kaitannya di dunia perpustakaan klasifikasi diartikan sebagai kegiatan pengelompokkan bahan pustaka berdasarkan ciri-ciri yang sama, misalnya pengarang, fisik, isi sebagainya.. Pada dasarnya di perpustakaan dikenal ada 2 (dua) jenis kegiatan klasifikasi. Klasifikasi Fundamental (Fundamental Classification) yaitu klasifikasi bahan pustaka berdasarkan subyek/isi buku, sebab pada dasarnya pemakai perpustakaan lebih banyak mencari informasi tentang subyek tertentu. Klasifikasi Artifisial (Artificial Classification), yaitu klasifikasi bahan pustaka berdasarkan ciri-ciri yang ada pada bahan pustaka. Misalnya klasifikasi berdasarkan warna, ukuran dan sebagainya. Decision Tree (C4.5) adalah sebuah struktur pohon, di mana setiap node pohon merepresentasikan atribut yang telah diuji, setiap cabang merupakan suatu pembagian hasil uji, dan node daun (leaf) merepresentasikan kelompok kelas tertentu. Level node teratas dari sebuah Decision Tree (C4.5) adalah node akar (root) yang biasanya berupa atribut yang paling memiliki pengaruh terbesar pada suatu kelas tertentu.

Rumus untuk mencari Entropy:

$$
\operatorname{Entropy}(S)=\sum_{i=1}^{x}-p i \times \log ^{2} p i
$$

Keterangan Konsep Entropy:

$\mathrm{S}=$ Himpunan kasus

$\mathrm{i}=$ Fitur

$\mathrm{n}=$ Jumlah partisi S

pi $=$ Proporsi Si terhadap S

Rumus untuk mencari Gain :

$$
\operatorname{Gain}(S, a)=\operatorname{Entropy}(S) \sum_{i=1}^{x} \frac{|S i|}{|S|} x \operatorname{Entropy}(S i)
$$

Keterangan Konsep Gain :

$\mathrm{S}=$ Himpunan kasus

$\mathrm{I}=$ Atribut

$\mathrm{n}=$ Jumlah partisi atribut $\mathrm{A}$

$\mathrm{Si}=$ Proporsi Si terhadap S

$S=$ Jumlah kasus dalam $S$

K-Naive Bayes merupakan sebuah pengklasifikasi probabilitas sederhana yang mengaplikasikan Teorema Bayes dengan asumsi ketidak tergantungan (independent) yang tinggi. Keuntungan penggunan K-Naive Bayes adalah bahwa metoda ini hanya membutuhkan jumlah data pelatihan (training data) yang kecil untuk menentukan estimasi parameter yang diperlukan dalam proses pengklasifikasian. Untuk situasi ini, menilai kemungkinan bahwa sebuah data yang sudah ada untuk kemungkinan sebuah keputusan menggunakan algoritma K-Naive Bayes [5].

Rumus mencari Probabiliti :

$$
P(H \mid X)=\frac{P(X \mid H) \cdot P(H)}{P(X)}
$$


Di mana :

$X \quad$ : Data dengan class yang belum diketahui

$H \quad$ : Hipotesis data merupakan suatu class spesifik

$P(H \mid X)$ : Probabilitas hipotesis $H$ berdasar kondisi $X$ (posteriori probabilitas)

$P(H) \quad$ : Probabilitas hipotesis $H$ (prior probabilitas)

$P(X \mid H)$ : Probabilitas $X$ berdasarkan kondisi pada hipotesis $H$

$P(X) \quad$ : Probabilitas $X$

Rumus Mencari Peluang :

$$
P\left(X i=x i \mid Y=y_{j}\right)=\frac{1}{\sqrt{2} \pi \sigma_{i j}} e^{-\frac{\left(x_{i}-\mu_{i j}\right)^{2}}{2 \sigma^{2} i j}}
$$

Di mana :

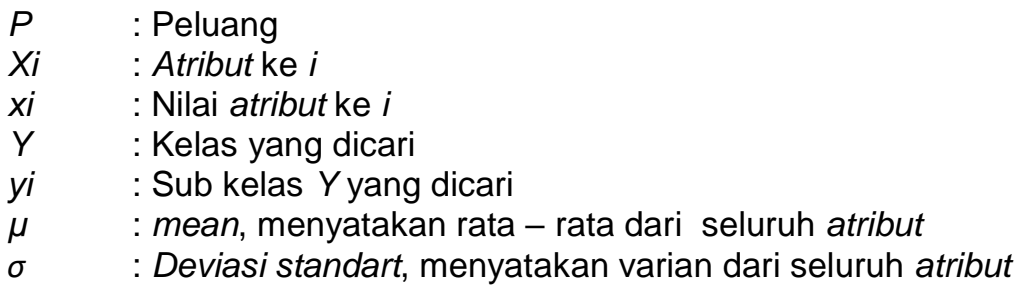

\subsection{Rapidminer}

Rapidminer adalah software analisis data mining yang digunakan untuk menganalisa data dan mendukung berbagai teknik data mining. Rapidminer ini digunakan untuk aplikasi industri, penelitian, pelatihan, pengembangan aplikasi dan pendidikan. Rapidminer mengandung sekitar 100 skema pembelajaran untuk analisis klastering, klasifikasi dan regresi. Ini mendukung sekitar 22 format file seperti .xls, .csv dan masih banyak data pendukung lainnya [6].

\subsection{Implementasi Klasifikasi Profil PMB Mahasiswa tingkat}

\subsubsection{Decision Tree (C4.5)}

Data profil PMB mahasiswa yang sudah ada dari file excel dan dikoneksikan ke Rapidminer melalui read excel. Di Rapidminer fitur yang digunakan untuk menampilkan fitur yang diinginkan disebut vektor. Pada penelitian algoritma ini atribut yang digunakan adalah Jurusan sekarang sebagai klas tujuan, jurusan asal dan Nem. Data yang diteliti sebanyak 1504 profil PMB mahasiswa.

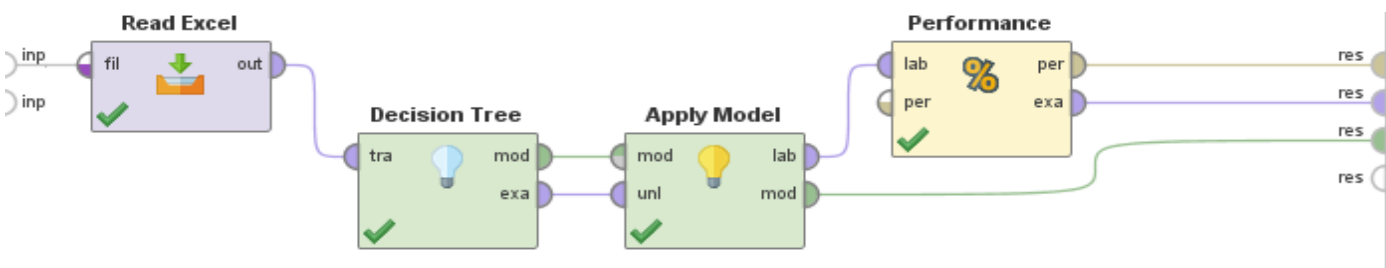

Gambar 1. Struktur Untuk Analisa Decision Tree (C4.5)

Pada Gambar 1. Data dari file excel diimport menggunakan menggunakan fitur Read Excel, setelah itu dikoneksikan ke fitur Decision Tree untuk menerapkan data yang diteliti menggunakan algoritma, selanjutnya ditambah fitur Apply Model untuk mensetujui model algoritma yang 
digunakan, dan ditambah fitur Performance untuk menampilkan performa dari algoritma yang diterapkan (contoh : akurasi). Hasil pohon keputusan menggunakan Rapidminer :

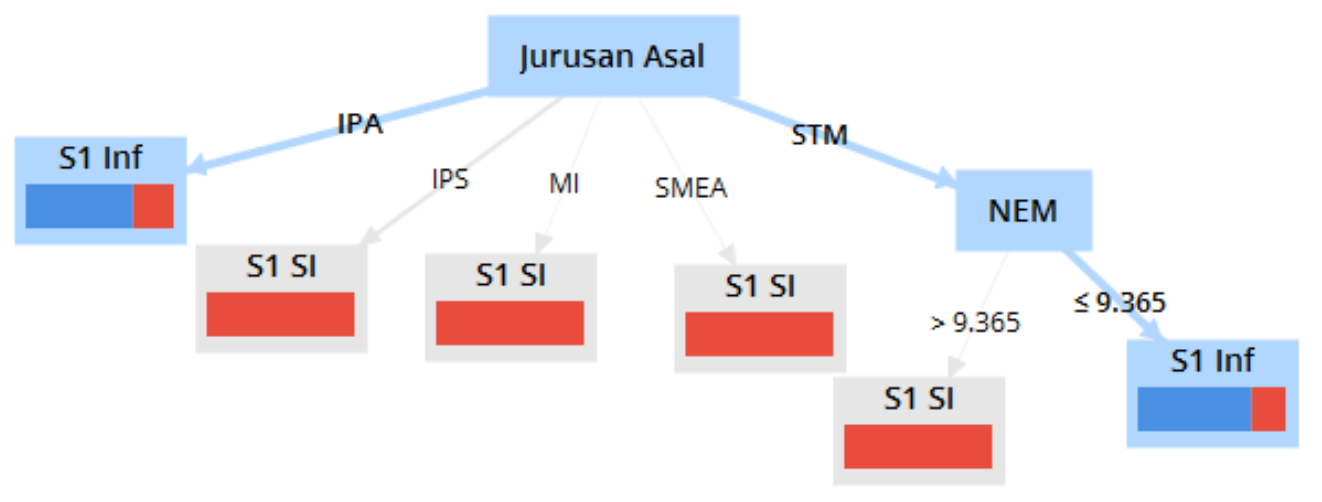

Gambar 2. Pohon Keputusan

\subsubsection{K-Naive Bayes}

Data profil PMB mahasiswa yang sudah ada dari file excel dan dikoneksikan ke Rapidminer melalui read excel. Susunan struktur antara Decision Tree (C4.5) dengan K-Naive Bayes hampir sama yang dirubah hanya fitur algoritmanya.

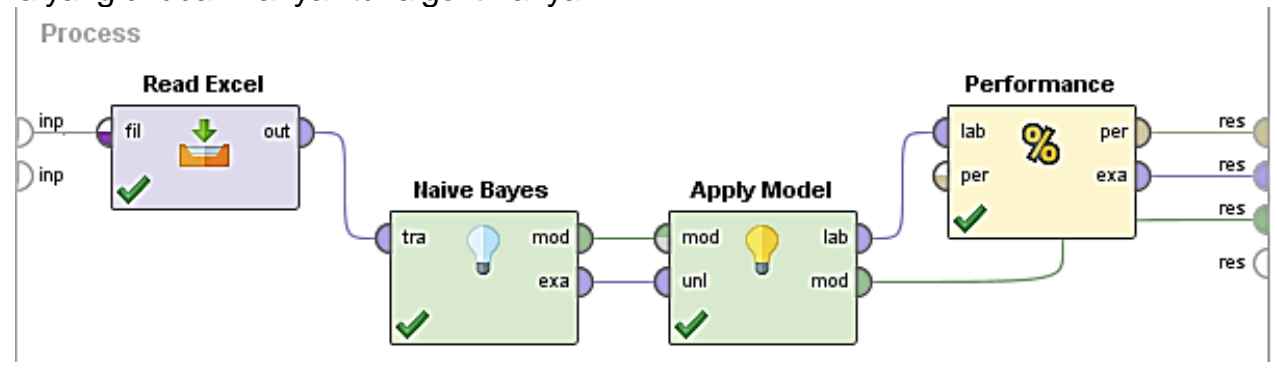

Gambar 3. Struktur Untuk Analisa K-Naive Bayes

Pada Gambar 3. Data dari file excel diimport menggunakan menggunakan fitur Read Excel, setelah itu dikoneksikan ke fitur Naive Bayes untuk menerapkan data yang diteliti menggunakan algoritma, selanjutnya ditambah fitur Apply Model untuk mensetujui model algoritma yang digunakan, dan selanjutnya ditambah fitur Performance untuk menampilkan performa dari algoritma yang diterapkan. Hasil Analisa K-Naive Bayes menggunakan Rapidminer :

\section{SimpleDistribution}

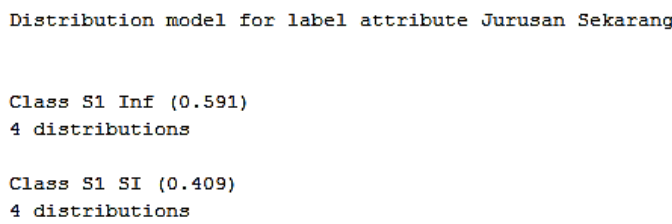

\section{Gambar 4. Distribusi atribut jurusan sekarang}




\subsection{Implementasi Pembuktian SMK di Madiun}

\subsubsection{Decision Tree (C4.5)}

Profil PMB Mahasiswa dari tahun 2014 sampai 2017 setelah diteliti terdapat 1 siswa angkatan tahun 2015 yang berasal dari SMK di Madiun, sehingga pembuktian diterapkan menggunakan data dari sekolahan tersebut. Pembuktian diterapkan di SMK di Madiun yang sekarang mempunyai dua keahlian yaitu Multimedia dan Perbankan. Siswa yang di ambil lulusan tahun 2015 sebanyak 27 siswa, terdiri dari 19 jurusan Multimedia dan 8 jurusan perbankan.

Tabel 1. Mencari entropy dan gain

\begin{tabular}{|c|c|c|c|c|c|}
\hline & JML & $\mathrm{Ya}$ & Tidak & \multirow{2}{*}{ Entropy } & \multirow{2}{*}{ Gain } \\
\hline & \multicolumn{3}{|l|}{ Kasus } & & \\
\hline TOTAL & 27 & 1 & 26 & 0,228538144 & \\
\hline Pekerjaan Orang Tua & & & & & 0,0446195 \\
\hline Dagang & 2 & 0 & 2 & 0 & \\
\hline Swasta & 12 & 1 & 11 & 0,41381685 & \\
\hline Serabutan & 1 & 0 & 1 & 0 & \\
\hline Wiraswasta & 2 & 0 & 2 & 0 & \\
\hline PNS & 3 & 0 & 3 & 0 & \\
\hline Buruh Tani & 3 & 0 & 3 & 0 & \\
\hline Petani & 3 & 0 & 3 & 0 & \\
\hline Ibu Rumah Tangga & 1 & 0 & 1 & 0 & \\
\hline Jurusan & & & & & 0,0192058 \\
\hline Mulitimedia & 19 & 1 & 18 & 0,297472249 & \\
\hline Perbankan & 8 & 0 & 8 & 0 & \\
\hline
\end{tabular}

Pada Tabel 1. Menjelaskan hasil perhitungan mencari entropy dan gain, perhitungan mencari nilai entropy pekerjaan orang tua dengan keterangan swasta yaitu :

$$
\begin{aligned}
& \text { Entropy }(S)=\sum_{i=1}^{x}-p i \times \log ^{2} p i \\
& =\left(\left(-\frac{1}{12}\right) \times \log 2\left(\frac{1}{12}\right)+\left(-\frac{11}{12}\right) \times \log 2\left(\frac{11}{12}\right)\right)=0,41381685
\end{aligned}
$$

Perhitungan mencari gain dari pekerjaan orang tua yaitu :

$$
\begin{aligned}
& \operatorname{Gain}(S, a)=\operatorname{Entropy}(S) \sum_{i=1}^{x} \frac{|S i|}{|S|} x \text { Entropy }(S i) \\
& =0,044619544-\left(\begin{array}{l}
\left(\frac{5}{27} \times 0\right)+\left(\frac{12}{27} \times 0,41381685\right)+\left(\frac{1}{27} \times 0\right)+\left(\frac{2}{27} \times 0\right) \\
+\left(\frac{3}{27} \times 0\right)+\left(\frac{3}{27} \times 0\right)+\left(\frac{3}{27} \times 0\right)+\left(\frac{1}{27} \times 0\right)
\end{array}\right) \\
& =0,044619544
\end{aligned}
$$


Setelah selesai mencari entropy dan gain maka akan bisa digambar pohon keputusan dari tabel pekerjaan orang tua dengan keterangan pada gambar 5 yaitu :

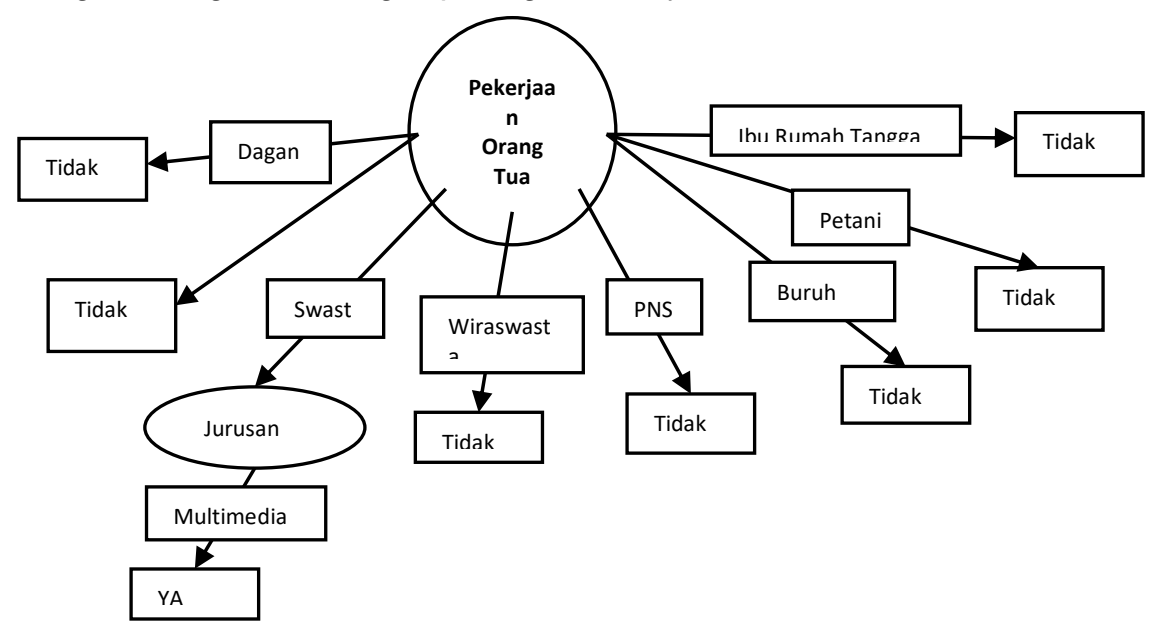

Gambar 5. Pohon Keputusan Decision Tree (C4.5)

Setelah mencari entropy dan gain bisa ditarik kesimpulan pohon keputusan Decision Tree (C4.5) pada Gambar 5. Pada gambar tersebut dengan atribut swasta masih bisa dicari sehingga ketemu jurusan multimedia dengan keterangan "Ya".

\subsubsection{K-Naive Bayes}

Pembuktian perhitungan dengan K-Naive Bayes ini menggunakan excel dengan rumus formula yang sudah tersedia dari Tabel 2. Perhitungan K-Naive Bayes berbeda dengan Decision Tree (C4.5), algoritma ini menghitung semua data bersama tanpa mencari nilai tertinggi terlebih dahulu.

Tabel 2. Mencari Probabiliti Tiap Atribut

\begin{tabular}{l|rc}
\hline YA/TIDAK & 0,037037 & 0,962962963 \\
\hline P(V= $\downarrow \mid \ldots$ & & \\
Dagang & $\ldots$ | C=Ya) & $\ldots$ | C=Tidak $)$ \\
Swasta & 0 & 0,074074074 \\
\hline Serabutan & 0,037037 & 0,407407407 \\
Wiraswasta & 0 & 0,037037037 \\
PNS & 0 & 0,074074074 \\
Buruh Tani & 0 & 0,111111111 \\
Petani & 0 & 0,111111111 \\
lbu Rumah & 0 & 0,111111111 \\
\hline Tangga & 0 & 0,037037037 \\
\hline
\end{tabular}

\begin{tabular}{c|rc}
\hline $\mathbf{P}(\mathbf{E}=\downarrow \mid \ldots$ & $\ldots \mid \mathbf{C}=\mathbf{Y a})$ & $\ldots$ | C=Tidak $)$ \\
\hline Multimedia & 0,037037 & 0,818181818 \\
\hline Perbankan & 0 & 0,363636364 \\
\hline
\end{tabular}


Perhitungan mencari probabiliti pada atribut swasta dengan keterangan "Ya" :

$$
P(H \mid X)=\frac{P(X \mid H) \cdot P(H)}{P(X)}=\frac{1}{27}=0,037037
$$

Perhitungan mencari peluang :

$$
P\left(X i=x i \mid Y=y_{j}\right)=\frac{1}{\sqrt{2} \pi \sigma_{i j}} e^{-\frac{\left(x_{i}-\mu_{i j}\right)^{2}}{2 \sigma^{2} i j}}
$$

$=0,962962963+0,407407407+0,818181818=0,320987654$

Karena dengan keterangan nama Alil Fachrul dengan nilai TIDAK lebih tinggi dari nilai YA maka dengan keterangan YA berubah menjadi TIDAK. Dengan keterangan sebagai berikut :

\begin{tabular}{|c|c|c|c|}
\hline Sebelum & Class (sesudah) & $p(X \mid Y a)$ & $p(X \mid$ Tidak $)$ \\
\hline Tidak & Tidak & 0 & 0,14266118 \\
\hline Tidak & Tidak & 0 & 0,038907594 \\
\hline Tidak & Tidak & 0 & 0,14266118 \\
\hline Tidak & Tidak & 0 & 0,038907594 \\
\hline Tidak & Tidak & 0 & 0,038907594 \\
\hline Tidak & Tidak & 0 & 0,012969198 \\
\hline Tidak & Tidak & 0 & 0,14266118 \\
\hline Tidak & Tidak & 0 & 0,038907594 \\
\hline Tidak & Tidak & 0 & 0,058361392 \\
\hline Tidak & Tidak & 0 & 0,029180696 \\
\hline Tidak & Tidak & 0 & 0,320987654 \\
\hline Tidak & Tidak & 0 & 0,058361392 \\
\hline Tidak & Tidak & 0 & 0,087542088 \\
\hline Tidak & Tidak & 0 & 0,058361392 \\
\hline Tidak & Tidak & 0 & 0,320987654 \\
\hline Tidak & Tidak & 0 & 0,087542088 \\
\hline Tidak & Tidak & 0 & 0,087542088 \\
\hline Tidak & Tidak & 0 & 0,320987654 \\
\hline Tidak & Tidak & 0 & 0,058361392 \\
\hline Tidak & Tidak & 0 & 0,087542088 \\
\hline Tidak & Tidak & 0 & 0,320987654 \\
\hline Tidak & Tidak & 0 & 0,320987654 \\
\hline Tidak & Tidak & 0 & 0,320987654 \\
\hline Tidak & Tidak & 0 & 0,087542088 \\
\hline Tidak & Tidak & 0 & 0,320987654 \\
\hline Tidak & Tidak & 0 & 0,320987654 \\
\hline $\mathrm{Ya}$ & Tidak & 0 & 0,320987654 \\
\hline
\end{tabular}

Tabel 3. Peluang K-Naive Bayes 
Pada Tabel 2, kolom Sebelum adalah data sebelum diteliti dan pada kolom Class (sesudah) adalah data setelah diteliti. Jika nilai pada kolom $p(X \mid Y a)$ lebih kecil dari $p(X \mid$ Tidak) maka kolom Class (sesudah) menjadi keterangan "Tidak" dan sebaliknya. Perubahan keterangan dari "Ya" menjadi "Tidak" bisa dilihat pada Tabel 2 baris yang terakhir karena kolom $\mathrm{p}(\mathrm{X} \mid \mathrm{Ya})$ lebih besar dari $\mathrm{p}(\mathrm{X} \mid$ Tidak) yaitu 0 lebih besar dari 0,320987654.

\section{HASIL DAN PEMBAHASAN}

Analisa data tingkat Universita di Yogyakarta dan SMK di Madiun, pada data tingkat Universita di Yogyakarta mempunyai jurusan S1 Teknik Informatika dengan jumlah 1143 sedangkan S1 Sistem Informasi berjumlah 361 semuanya berjumlah 1504 data.

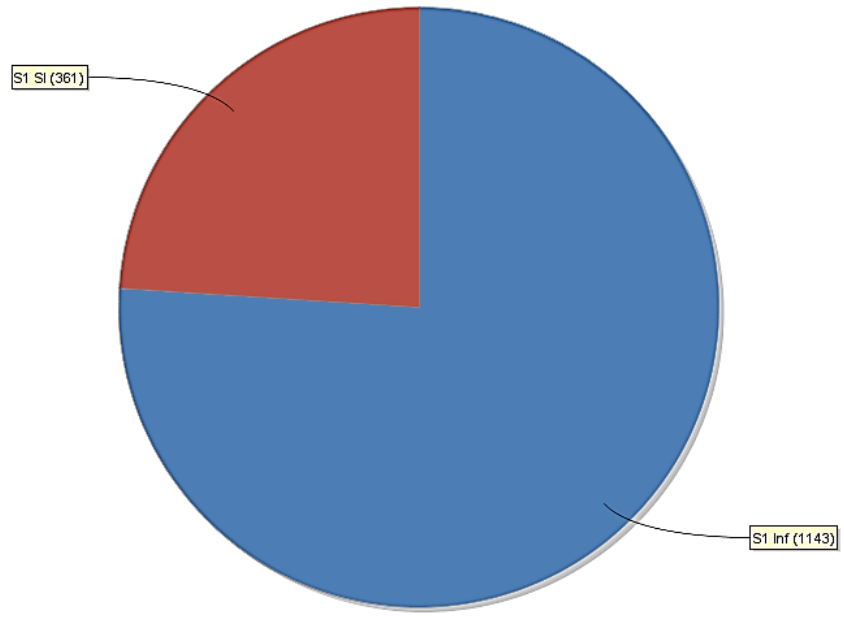

Gambar 5. Grafik Profil PMB mahasiswa tingkat Universita di Yogyakarta

Pada gambar 5 menunjukkan data histori PMB Mahasiswa baru yang mendominasi adalah dari jurusan S1 Inf. Dan pada jurusan S1 Inf yang mendominasi jurusan asal adalah IPA, sehingga pada PMB yang akan datang bisa difokuskan promosi ke SMA jurusan IPA.

Tabel 4. Perbandingan Algoritma Decision Tree (C4.5) dan Algoritma K-Naive Bayes

\begin{tabular}{lccc}
\hline & $\begin{array}{c}\text { Tingkat } \\
\text { Universitas }\end{array}$ & $\begin{array}{c}\text { Tingkat Universitas } \\
\text { (Sampel) }\end{array}$ & SMK di Madiun \\
\hline \multicolumn{2}{l}{ Decision Tree (C4.5) } & & 20 \\
\hline Data Record & 988 & $100 \%$ & 27 \\
\hline Akurasi & $81,84 \%$ & $0 \%$ & $96,30 \%$ \\
\hline Akurasi Error & $18,16 \%$ & 0 detik & 0 detik \\
\hline Waktu & 3 detik & & 27 \\
\hline K-Naive Bayes & & 20 & $96.30 \%$ \\
\hline Data Record & 1504 & $100 \%$ & $3.70 \%$ \\
\hline Akurasi & $85,12 \%$ & $0 \%$ & 0 detik \\
\hline Akurasi Error & $14,88 \%$ & 0 detik & \\
\hline Waktu & 0 detik & & \\
\hline
\end{tabular}


Penelitian ini menggunaka Rapidminer dengan hasil pada Tabel 4. Menunjukkan tingkat akurasi Rapidminer dengan data yang lebih besar yaitu 1504 data menggunakan Algoritma Decision Tree (C4.5) mempunyai tingkat akurasi yang lebih kecil dibanding dengan algoritma K-Naive Bayes waktu yang dibutuhkan, K-Naive Bayes lebih cepat dibanding dengan Decision Tree(C4.5). Sedangkan menggunakan data yang lebih kecil yaitu 20 dan 27 data, kedua algoritma mempunyai tingkat akurasi sama.

\section{KESIMPULAN}

Kesimpulan dari penelitian ini adalah dengan membandingkan dua algoritma, K-Naive Bayes yang mempunyai tingkat akurasi yang lebih baik dibanding dengan algoritma Decision Tree (C4.5) mempunyai akurasi $81,84 \%$ dan akurasi error $18,16 \%$, sedangkan K-Naive Bayes $85,12 \%$ dan akurasi error 14,88\%. Sedangkan dengan data yang lebih kecil Decision Tree (C4.5) mempunyai akurasi $100 \%$ sedangkan kan K-Naive Bayes mempunyai akurasi yang sama dengan Decision Tree (C4.5) yaitu 100\%. Dari segi kecepatan Decision Tree (C4.5) lebih lambat menganalisa dibanding dengan K-Naive Bayes. Karena perbandingan hanya 3 detik dengan menggunakan software Rapidminer sehingga waktu kurang signifikan pada penelitian ini.

\section{UCAPAN TERIMA KASIH}

Terimakasi kepada instansi terkait yang telah membantu menyediakan data, kepada temanteman dan dosen pembimbing yang telah membimbing penelitian ini sehingga bisa selesai dengan baik walaupun penelitian ini masih kurang sempurna.

\section{DAFTAR PUSTAKA}

[1] Angra, S. and Ahuja, S. (2016) 'Analysis of student's data using rapid miner', Journal on Today's Ideas - Tomorrow's Technologies, 4(1), pp. 49-58. doi: 10.15415/jotitt.2016.41004.

[2] Brauning, M. et al. (2017) 'Lexicographic preferences for predictive modeling of human decision making: A new machine learning method with an application in accounting', European Journal of Operational Research, 258(1), pp. 295-306. doi: 10.1016/j.ejor.2016.08.055.

[3] Chen, L. and Wang, S. (2012) 'Automated Feature Weighting In Naive Bayes For High-dimensional Data Classification', Proceedings of the ACM International Conference on Information and Knowledge Management, pp. 1243-1252. doi: 10.1145/2396761.2398426.

[4] Jannach, D., Jugovac, M. and Lerche, L. (2016) 'Supporting the Design of Machine Learning Workflows with a Recommendation System', ACM Transactions on Interactive Intelligent Systems, 6(1), pp. 1-35. doi: 10.1145/2852082.

[5] Kitcharoen, N. et al. (2013) 'RapidMiner Framework for Manufacturing DataAnalysis on the Cloud', 2013 10th International Joint Conference on Computer Science and Software Engineering (JCSSE), pp. 1-6. doi: 10.1109/JCSSE.2013.6567336.

[6] S. Rana and A. Singh (2016) 'Comparative Analysis of Sentiment Orientation Using SVM and Naive Bayes Techniques', (October), pp. 106-111. 